\title{
O INSTITUTO JURÍDICO DA INDICAÇÃO GEOGRÁFICA NA PROMOÇÃO DO DESENVOLVIMENTO REGIONAL: O CASO DOS CRISTAIS ARTESANAIS DA REGIÃO DE BLUMENAU 1
}

\author{
THE LEGAL INSTITUTION OF GEOGRAPHICAL \\ INDICATION IN PROMOTING REGIONAL \\ DEVELOPMENT: THE CASE OF HANDMADECRYSTALS \\ IN THE REGION OF BLUMENAU
}

\author{
Patrícia Luiza Kegel \\ Universidade Regional de Blumenau - Blumenau - SC - Brasil
}

Suelen Carls

Universidade Federal de Santa Catarina - Florianópolis - SC - Brasil

\begin{abstract}
Resumo: O objetivo deste artigo é refletir sobre a utilização do instituto jurídico da Indicação Geográfica - IG como estratégia de desenvolvimento regional, ao possibilitar a diferenciação e proteção da produção local em um mercado consumidor globalizado e competitivo. A perspectiva de sua utilização no setor de cristais artesanais da região de Blumenau no Estado de Santa Catarina representa uma alternativa para contornar a atual crise e seus efeitos negativos, ao proporcionar maior sustentabilidade econômica e gerar condições de crescimento de renda e desenvolvimento local.
\end{abstract}

Palavras-chave: Indicação Geográfica. Direitos de Propriedade Intelectual. Desenvolvimento Regional. Cristais artesanais.

\footnotetext{
1 Este artigo resulta de dissertação defendida no Programa de Pós-Graduação em Desenvolvimento Regional da Universidade Regional de Blumenau (PPGDR/FURB), intitulada "O aproveitamento da Indicação Geográfica na promoção de desenvolvimento regional: o caso dos cristais artesanais da região de Blumenau" e desenvolvida com apoio da Coordenação de Aperfeiçoamento de Pessoal de Nível Superior (CAPES).
} 
Abstract: The objective of this paper is to discuss the use of the legal institution of Geographical Indication as a regional development strategy to enable differentiation and protection of local production in a globalized and competitive consumer market. The prospect of its application in handmade crystal sector in the region of Blumenau, in south Brazil, is an alternative to overcome the current crisis of the sector and its negative effects, to provide greater economic sustainability and create conditions for growth and local development.

Keywords: Geographical Indication. Intellectual Property Rights. Regional Development. Handmadecrystals.

\section{INTRODUÇÃO}

O pressuposto teórico deste artigo reside na compreensão de que o desenvolvimento não pode ser subdividido em várias dimensões distintas e sem nexo causal entre si. Ou seja, o desenvolvimento econômico, social e humano não pode ser dissociado do desenvolvimento jurídico da sociedade, na medida em que o Direito, enquanto fenômeno normativo da sociedade humana, está imbricado a todas as demais manifestações da experiência social.

Essas reflexões, portanto, estão inseridas em um tema que não pode ser negligenciado no debate sobre as estratégias de desenvolvimento para determinado país ou região, em especial as necessárias interconexões do desenvolvimento com o arcabouço jurídico que o delimita. Nesse sentido, integra a agenda de debates como um conceito fundamental para a elaboração de políticas públicas, tanto a nível internacional quanto no Brasil (BARRAL, 2006).

Ou seja, de modo amplo, as instituições jurídicas influenciam o processo de desenvolvimento econômico através da definição do ambiente institucional no qual este ocorre, em especial, por meio da fixação de regras jurídicas que estabelecem as bases sobre as quais se organizam as relações de produção, a troca e a distribuição da atividade econômica.

Em um ambiente de economia global, de competição acirrada e mudança dos paradigmas do estado-nação, torna-se imprescindível estudar o impacto que o ambiente jurídico produz não apenas sobre a atividade econômica, mas, em especial, sobre as opções de interação entre indivíduos e grupos e, como tal, pesquisar seu potencial para alcançar o desenvolvimento em suas várias dimensões. 
Nesse contexto, a proposta deste artigo é refletir sobre os mecanismos por meio dos quais as relações entre Direito e Desenvolvimento se manifestam de modo concreto no território, ao estudar o instituto jurídico da IG, e como ele pode tornar-se indutor do desenvolvimento em um caso específico de IG para produtos não agroalimentares no Brasil: o setor de cristais artesanais da região de Blumenau - SC.

Para tanto, o artigo está dividido em três seções além desta Introdução e das Considerações Finais. A primeira, que aborda a interconexão das dimensões espacial, econômica e jurídica do desenvolvimento e suas interfaces com a IG. A segunda, que irá expor a especificidade dos Direitos de Propriedade Intelectual, em cujo âmbito está inserida a IG, a imperatividade de sua proteção jurídica e sua potencialidade como indutora de desenvolvimento econômico e requalificação territorial. A terceira seção tem por objetivo verificar se o setor de cristais artesanais da região de Blumenau, no Estado de Santa Catarina, reúne condições de conseguir seu reconhecimento como IG. Por fim, as Considerações Finais apontam para os eventuais impactos de uma IG na promoção de dinâmicas socioeconômicas que resultem em desenvolvimento e a importância da proteção dos ativos intelectuais de um país.

\section{DIMENSÕES DO DESENVOLVIMENTO}

O debate sobre o desenvolvimento e suas dimensões necessita de uma delimitação prévia de seu sentido. Nesse caso, um denominador conceitual mínimo comum que justifique a opção de pesquisar a IG sob suas distintas perspectivas.

Nesse sentido, por desenvolvimento, pode-se entender, inicialmente, o processo de mudança social viabilizado pela mobilização de recursos objetivando alcançar fins previamente estabelecidos por uma coletividade (SOUZA; THEIS, 2009, p. 12). Por outro lado, para Seers (1970 apud BOISIER, 2001, p. 2, grifo nosso), o desenvolvimento é "um conceito repleto de juízos de valor", sendo, geralmente, utilizado com algum complemento adjetivo, como econômico, humano, descentralizado, endógeno, regional, político ou social, dentre outros. Dessa forma, em virtude da sua subjetividade, o desenvolvimento pode 
ser estudado a partir das mais diversas dimensões, optando-se, neste trabalho, pelas dimensões espacial, econômica e jurídica, na medida em que suas interconexões com a IG permitem uma melhor apreensão da especificidade e possibilidades deste instituto jurídico.

A partir dessa delimitação conceitual, a ideia de localidade vem assumindo um papel de extrema importância no debate sobre o desenvolvimento da atividade produtiva, até mesmo nas estratégias utilizadas pelos atores econômicos, de forma individual ou coletivamente (CALDAS; CERQUEIRA; PERIN, 2005, p. 14). Ou seja, o desenvolvimento sempre será localizado, uma vez que requer, para a construção de um referencial de atuação, um espaço geograficamente delimitado. E apesar de haver uma diversidade de sentidos ou de alcance específico para os termos "espaço", "território" e "região", utiliza-se como referência a delimitação geográfica na qual o homem atua, independentemente do termo utilizado.

Nesse contexto, o termo desenvolvimento regional, segundo Siedenberg (2006), aparece relacionado tanto a um processo quanto a um estágio. O processo refere-se às mudanças sociais e econômicas que ocorrem numa determinada região, e nas quais coexistem a dimensão temporal e a dimensão espacial. As mudanças podem ser de ordem qualitativa e/ou quantitativa, podendo ser mensuradas por meio de diferentes indicadores e parâmetros, indicando, assim, seu estágio dentro do processo (SIEDENBERG, 2006). Já a dimensão temporal estaria relacionada a mudanças que ocorrem com o passar do tempo, enquanto que a espacial seria variável de acordo com o enfoque pretendido. Nesse caso, são vários os recortes que podem ser utilizados, desde uma dimensão verdadeiramente continental, até dimensões intermediárias entre as delimitações administrativas de um país e seus estadosmembros ou entre estados e municípios (SIEDENBERG, 2006).

Por outro lado, existe a perspectiva de que o sucesso de uma estratégia de desenvolvimento esteja acoplado, em cada região, às características singulares que a distinguem das outras, e que, portanto, devem ser utilizadas a seu favor.

Dentre essas características, encontra-se, inicialmente, a interrelação dos atores sociais, os quais, em se tratando de desenvolvimento localizado, são os agentes sociais e econômicos-indivíduos e instituições -, que realizam ou desempenham atividades ou, então, 
mantêm relações num determinado território (SABOURIN 2002). Mas também a utilização de recursos existentes, tais como mão de obra e atrativos turísticos, por exemplo, e o potencial de desenvolvimento de novos recursos a partir do capital cultural ali localizado.

Para Bourdieu (1997) essa é a segunda mais importante acepção do termo capital, ficando atrás apenas da acepção econômica. Esse capital, segundo ele, pode existir sob três formas: (a) incorporado, no qual se verifica um processo de interiorização nos marcos do processo de ensino e aprendizagem; (b) objetivado, aquele que é possível transferir por meio de um suporte físico; (c) institucionalizado, aquele percebido por meio de títulos garantidos legalmente.

E nesse cenário que se verifica a necessidade de se estabelecer a dimensão espacial do desenvolvimento, delimitado por um recorte geográfico, seja ele chamado de desenvolvimento local, regional ou territorial.

Assim, o desenvolvimento local é caracterizado, segundo Boisier (2006b), por um conjunto de particularidades endógenas, como autonomia, reinvestimento, inovação, identidade e seus impactos na escala e na funcionalidade das organizações, mas também pelo papel dos recursos, especialmente os não materiais, o que inclui o tecido social, seus agentes e suas relações, sejam elas diretas ou mediatas. E, finalmente, pela cultura local, cuja sinergia permite o progresso sistemático do território. Para o autor, portanto, o desenvolvimento local deriva do cruzamento de dois emergentes sistêmicos: um, que resulta da interação do território com sua vizinhança e outro, que procede da interação do sistema (desenvolvimento) (BOISIER, 2006b).

Nessa perspectiva, o desenvolvimento não se materializa apenas por meio de instrumentos homogêneos que podem ser aplicados a qualquer área geográfica delimitada. É fundamental a existência de um conjunto de fatores que potencialize a dinâmica interna do território e suas potencialidades.

Entre os fatores que potencializam o desenvolvimento no território, encontra-se, indiscutivelmente, a atividade econômica. Nesse caso, a correlação entre economia e desenvolvimento, ou desenvolvimento econômico, foi a primeira a ser efetuada para explicar a origem do crescimento de alguns indicadores econômicos e de bem 
estar, tais como: renda per capita e tamanho do mercado, mas também acesso à educação, saúde e infraestrutura urbana.

Sua origem encontra-se já no século XVI, quando existia forte percepção de que os fatores de crescimento estavam intensamente vinculados à questão do fortalecimento do Estado Nacional que, à época, consagrava seu poder por meio da expansão marítima. Dessa concepção de desenvolvimento, partiam significativas relações com os poderes político e militar que, a partir do liberalismo, consolida-se como poder econômico (BARRAL, 2010). Posteriormente, esta visão economicista do desenvolvimento também pode ser encontrada em Adam Smith quando, em $A$ riqueza das nações de 1776 , postula que a razão do crescimento de uma determinada nação estaria relacionada à capacidade que ela possuía para gerar excedentes no processo produtivo.

Mesmo que numa perspectiva e período histórico bastante diverso, Furtado (1981), em sua obra $O$ mito do desenvolvimento econômico, refuta a visão historicista então vigente, e destaca fatores não econômicos como primordiais para o desenvolvimento. Alerta para a inexistência de uma receita ideal ou natural para o desenvolvimento, na medida em que ele pode ocorrer de maneira desigual, e se dedica a uma explanação acerca das estruturas sociopolíticas que podem induzir ou retardar processos de desenvolvimento.

Para outro economista brasileiro preocupado com o tema, Bresser-Pereira, o desenvolvimento econômico tal qual se conhece, é um "processo econômico que envolve conceitos como o de taxa de lucro e de investimento produtivo, de trabalho assalariado e de consumo popular e de luxo, de inovação e de produtividade, que só fazem sentido a partir do capitalismo" (BRESSER-PEREIRA, 2006, p. 9). Dessa forma, o desenvolvimento econômico remete, genericamente, ao aumento da produção e da renda, que se entende indispensável para que a população possa ter acesso a outros bens igualmente necessários, como a saúde e o lazer.

Por outro lado, o processo de desenvolvimento econômico exige que sejam feitos ajustes institucionais, fiscais e jurídicos, incentivos para inovações, empreendedorismo e investimentos, bem como a existência condições para um sistema eficiente de produção, circulação e distribuição de bens e serviços à população. Assim, o desenvolvimento 
econômico é também um processo de transformação que exige mudanças em três níveis ou instâncias da sociedade: estrutural, institucional e cultural.

Nessa perspectiva, um dos grandes debates, tanto sob a ótica econômica, mas também política e social, tem sido sobre as causas do desenvolvimento econômico, que levam alguns países a aumentarem sua atividade econômica e tornarem-se ricos, enquanto outros permanecem estagnados e sem perspectivas de crescimento. Nesse caso, a evolução das teorias econômicas vem apontando para a importância crescente do quadro institucional, ou seja, em que o grau de desenvolvimento econômico depende de forma substancial da eficiência dos sistemas político e administrativo e, fundamentalmente, de um ambiente jurídico previsível e efetivo (KEGEL, P.L.; AMAL, M., 2009).

Nesse caso, a análise do papel das instituições e seu impacto sobre o desempenho das economias é essencial para compreender quais elementos podem explicar as diferenças nas taxas de crescimento e renda per capita entre os países.

Além disso, no que diz respeito ao aspecto institucional, assim como a dimensão espacial e econômica, o desenvolvimento possui uma dimensão jurídica bastante relevante, na medida em que, além de instrumento de solução de conflitos sociais, o Direito como ordem jurídica vigente, estabelece a organização do Estado, delimita seu sistema de governo, as estruturas de poder, os direitos fundamentais dos cidadãos, as regras que direcionam a atuação dos órgãos públicos e o conjunto normativo dentro do qual opera o mercado e as atividades a ele relacionadas (LOCATELLI, 2007b). Ou seja, as instituições jurídicas ocupam um lugar central na análise do processo de desenvolvimento econômico, pois definem o ambiente em que funciona a economia facilitando (ou não) a interação entre indivíduos e grupos sociais.

Nesse cenário, uma conexão importante entre Direito e desenvolvimento na sua acepção econômica reside no fato de que é a ordem jurídica a responsável pelo estabelecimento dos objetivos da ordem econômica nacional. Assim, limita a atuação do Estado e dos agentes econômicos e orienta suas ações no sentido do atendimento de diretrizes normativamente predeterminadas, as quais podem, como no Brasil, estarem estabelecidas na própria Constituição Federal. Além, 
portanto, de determinar os objetivos gerais da ordem econômica de um País, a ordem jurídica é a responsável por disponibilizar mecanismos para efetivá-los (LOCATELLI 2007b).

Essa mesma ordem jurídica vigente, consequentemente, é que detém a prerrogativa de determinar regras que delineiem a atuação dos agentes econômicos, a fim de que estes tenham capacidade de promover um desenvolvimento econômico equilibrado. Tais regras incidem sobre distintos âmbitos da atividade econômica, sendo que, entre as mais importantes, destacam-se a regulamentação dos setores da concorrência, investimentos estrangeiros, sistema de proteção ao consumidor, incentivos fiscais, flexibilidade ou rigidez das normas trabalhistas, segurança jurídica, tributação, liberdade contratual, direitos de propriedade e propriedade intelectual.

Nesse sentido, Sen (2000), ao discorrer sobre a importância do Direito na sua relação com o desenvolvimento, avalia que o capitalismo, por exemplo, somente emergiu quando o sistema jurídico foi capaz de Ihe proporcionar a aceitação dos direitos de propriedade, viabilizando, por conseguinte, uma economia baseada na propriedade privada. Igualmente, lembra que a eficiência das trocas, das mais diversas ordens, apenas é possibilitada por conta da liberdade de contratar e a previsibilidade de cumprimento desses contratos.

Ou seja, a relação benéfica entre Direito e desenvolvimento vai além das políticas de crescimento do Produto Interno Bruto - PIB de um País. Liga-se às questões de cooperação e solidariedade que transformam o capital econômico ${ }^{2}$ em capital social ${ }^{3}$, relações de confiança recíproca, menor corrupção e sonegação de impostos, impulsionando o desenvolvimento e possibilitando uma governabilidade democrática.

\footnotetext{
2Conforme Bourdieu (1989) o capital econômico apresenta-se sob a forma dos diferentes fatores de produção (terras, fábricas, trabalho) e do conjunto de bens econômicos (dinheiro, patrimônio, bens materiais), é acumulado, reproduzido e ampliado por meio de estratégias específicas de investimento econômico e de outras relacionadas a investimentos culturais e tem por objetivo a obtenção ou manutenção de relações sociais que possam possibilitar o estabelecimento de vínculos economicamente úteis.

3 Para Bourdieu (2003, p. 67): "O capital social é o conjunto de recursos atuais ou potenciais que estão ligados à posse de uma rede durável de relações, mais ou menos institucionalizadas de interconhecimento e de inter-reconhecimento".
}

Redes (St. Cruz Sul, Online), v. 20, n 3 - Suplemento, p. 293 - 313, set./dez. 2015300 
No entanto, o grau de eficácia do direito e de suas instituições no processo de desenvolvimento de um país depende, primordialmente, da maneira como são utilizados tais recursos. Nesse sentido, é profundamente pertinente a advertência de Locatelli (2007), para quem a inércia e ignorância da sociedade na busca pela efetivação de seus direitos, bem como no exercício de controle dos atos públicos, podem relativizar ou até mesmo solapar a efetividade da ordem jurídica como instrumento de desenvolvimento nacional.

Por outro lado, na interconexão das dimensões já referidas do desenvolvimento, é possível afirmar que como cada região possui especificidades e particularidades que a distinguem de outras, as estratégias de desenvolvimento devem estar conectadas a tais especificidades. Ou seja, a requalificação territorial é fruto, em grande parte, da utilização do potencial existente, com o apoio de instrumentos que permitam considerar as particularidades e atender às necessidades do território.

O empreendimento de esforços para o desenvolvimento de um território, portanto, pode se associar a estratégias de valorização de produtos locais de maneira distinta, quando a eles se conectam fatores específicos que diferenciam aquele território. Caso em que os mecanismos que podem levar ao desenvolvimento econômico estariam vinculados aos recursos territoriais inéditos sobre os quais se promove uma inovação e que estabelecem novas formas de relação com consumidores (FLORES, 2006).

Ou seja, a utilização das especificidades conectadas ao conjunto das relações sociais que permitem delimitar uma região com potencial para o reconhecimento de uma IG, pode constituir-se, também, no instrumento capaz de promover novas dinâmicas socioeconômicas no território.

Nesse cenário, o desenvolvimento objeto deste trabalho é aquele capaz de requalificar o território (dimensão especial) por meio de um instrumento jurídico (o instituto jurídico da IG), que seja relevante economicamente (dimensão econômica), uma vez que esta última dimensão é capaz de dar suporte a outras dimensões, como a social e a cultural, por exemplo. E, além disso, constitua-se em instrumento capaz de promover a coesão social por meio da cooperação entre os atores na busca de objetivos comuns. 


\section{DIREITOS DE PROPRIEDADE INTELECTUAL, INDICAÇÃO GEOGRÁFICA E DINÂMICAS SOCIOECONÔMICAS NO TERRITÓRIO}

Os Direitos de Propriedade Intelectual - DPI podem ser entendidos como sendo o conjunto de direitos que tem por finalidade a proteção das invenções ou criações do intelecto humano, não dependentes apenas da sua base material, mas fundamentalmente da intervenção intelectual humana. Para Pimentel e Barral (2007), os DPIs são ferramentas que permitem manter tanto uma posição jurídica (titularidade) quanto uma posição econômica (exclusividade).

A posição jurídica tem por função garantir ao titular do direito a possibilidade de recuperação dos investimentos realizados, sejam eles públicos ou privados, pois the assegura sanções contra eventuais violações. Já a posição econômica é afiançada por meio de uma situação privilegiada, na medida em que a posse de um direito de propriedade intelectual implica na exclusividade do processo industrial de comercialização de um produto ou serviço, de seu signo distintivo ou de obra literária, artística ou científica (PIMENTEL; BARRAL, 2007). Dessa forma, a proteção eficaz da propriedade intelectual proporcionada pelo sistema jurídico permite a sua comercialização, geração de lucros e investimento nos setores de pesquisa e inovação.

Tais circunstâncias fazem com que Países, sobretudo os mais industrializados, invistam maciçamente em pesquisa e desenvolvimento (P\&D) de produtos ou prestação de serviços com propriedade intelectual embutida, uma vez que lhes confere uma posição privilegiada no mercado e um maior retorno econômico, ao mesmo tempo em que gera mais empregos e renda para investimentos também em outros setores prioritários.

Nessa perspectiva, a existência de confiança na proteção da propriedade intelectual é fundamental para a formação de ciclos de aprendizado, geração de oportunidades vinculadas à área do conhecimento e, sobretudo, estímulo à pesquisa. Nesse sentido, a existência de normas nacionais coerentes em matéria de propriedade intelectual é de fundamental importância para o fomento do desenvolvimento a partir da proteção jurídica dos resultados obtidos por meio da intervenção humana criativa. 
Nesse horizonte, no grande grupo da propriedade intelectual, encontra-se a propriedade industrial. Esta, por sua vez, é composta por várias categorias, entre as quais os denominados signos distintivos, onde se encontra também a IG. Signos distintivos são sinais ${ }^{4}$ visualmente perceptíveis utilizados para identificar e distinguir produtos ou serviços, empresas, estabelecimentos, regiões ou localidades. A representação visual desses diversos sinais serve para identificar e distinguir produtos ou serviços de outros produtos e serviços dentro de um mercado extremamente competitivo. Em outros termos: "Os diversos sinais distintivos nasceram de um objetivo em comum: distinguir a origem (seja geográfica ou pessoal) de um produto" (CERDAN et al, 2010, p. 30).

Esse conjunto de signos distintivos é delimitado pela Lei de Propriedade Industrial - LPI n. 9.279 de 14 de maio de 1996, e abrange as indicações geográficas, as marcas de produto ou serviço, as marcas de certificação e as marcas coletivas. A principal diferença da IG em relação a outros signos distintivos é o fato de ser uma propriedade coletiva, na qual é obrigatória a ligação com um espaço geográfico delimitado, cuja história e tradição permitem a utilização desse sinal distintivo.

Por outro lado, esse gênero, a IG, pode ter duas subespécies: a Indicação de Procedência - IP e a Denominação de Origem - DO.

Os dois conceitos, contidos respectivamente nos artigos 177 e 178 da LPI, apresentam significativo grau de distinção. No caso de uma IP, por exemplo, é necessário comprovar apenas que a região tornou-se conhecida. Já no caso de uma DO, os critérios são mais rígidos e, por isso mesmo, o tempo de trabalho para obtenção do reconhecimento de uma DO é muito mais longo e exaustivo, pois há que se comprovar que o produto possui características únicas relativas ao local de produção, e que essas características possuem vinculação com fatores naturais e humanos presentes na área delimitada.

A IG de forma mais ampla, surge como fator decisivo para garantir a diferenciação de um produto e, por consequência, da própria região geográfica delimitada. É, portanto, a indicação utilizada em produtos

\footnotetext{
${ }^{4}$ Não é intenção no âmbito deste trabalho discorrer sobre a diferenciação conceitual entre signos e sinais distintivos.
} 
que apresentam uma origem geográfica específica, e que possuem qualidades e reputação vinculadas ao local geográfico (DUPIN, 2011 ).

Alguns elementos permeiam o processo de criação e consolidação de uma IG (DUPIN, 2011). Inicialmente, é necessário conquistar e ampliar a credibilidade dos consumidores em relação ao produto, ao mesmo tempo em que a cultura local é reforçada, conduzindo à reorganização do território e permitindo a criação de novas rendas indiretamente ligadas ao produto, como o turismo, e a promoção de outros bens com características regionais. Já a etapa posterior ao processo é possibilitar o uso de um selo de origem vinculado ao território. Dessa forma, a IG permite a agregação de valor e promoção diferenciada do produto, além de conferir visibilidade ao território de origem e oferecer condições para que outros bens e serviços desse território ganhem visibilidade e proporcionem renda.

Nesse contexto, são várias as possibilidades de uma IG operar como uma ferramenta de desenvolvimento regional sob os mais diversos aspectos, como o econômico. Inicialmente, pela adição de maior valor agregado aos produtos, estimulando o desenvolvimento de atividades lucrativas indiretas relacionadas às indicações geográficas reconhecidas. Mas também pela capacidade de melhorar a inserção desses produtos nos mercados interno e externo, provocando o incremento da renda dos produtores e comerciantes, o qual pode ser estendido a toda a comunidade local.

Para que esse conjunto de vantagens se concretize, no entanto, é essencial acentuar o caráter jurídico da IG para dimensionar a importância da sua proteção. Inicialmente, é importante registrar a importância do reconhecimento formal da IG formalmente no Instituto Nacional de Propriedade Industrial - INPI. O registro no INPI é de natureza meramente declaratória, significando que uma IG não é criada, apenas reconhecida. A importância do registro reside nas condições de manutenção de uma IG. Em especial, é fundamental a função de combate à falsificação, pois protege tanto o produtor que investiu na atividade econômica de acordo com o procedimento exigido quanto o consumidor que adquiriu um produto determinado.

A confiança gerada tanto no produtor quanto no consumidor de um produto com IG decorre do fato de que o seu registro no INPI deverá incluir, necessariamente, alguns itens. Destacam-se, nesse aspecto, o 
regulamento de uso do nome geográfico, o instrumento oficial que delimita a área geográfica, a descrição e características do produto, a comprovação de que os produtores atuam na área do pedido e exercem a atividade econômica que buscam proteger e, em especial, a existência de uma estrutura de controle da produção sobre os produtores que tenham o direito ao uso exclusivo da IG.

Ou seja, o registro possibilita a garantia da qualidade e eventual rastreabilidade do produto, em função da obrigatoriedade da existência de normas que delimitam o processo produtivo. Em outros termos, a produção de um produto com IG deve observar determinados critérios técnicos que assegurem a qualidade e as características do produto final. Sem a observância de tais critérios, a IG não poderá ser utilizada pelo produtor.

Com o registro, portanto, qualquer produtor que esteja estabelecido fora da área geográfica delimitada ou que, mesmo estando na área delimitada, produza em desacordo com o procedimento estabelecido, fica impedido de utilizar e/ou dar publicidade em seu produto da IG falsa. O principal objetivo é evitar a utilização não autorizada da IG, pois suas consequências mais diretas são a indução do consumidor em erro e o prejuízo do produtor com direito legítimo ao uso e que produza o bem de acordo com as normas estabelecidas. É o caso da Cachaça de Paraty no Rio de Janeiro, por exemplo, que sofria muito com as falsificações e que conseguiu combater tal situação após o registro da IG no INPI (LOCATELLI, 2007).

Nesse sentido, diversos outros grupos de produtores apontam que o reconhecimento da IG é um fator preponderante no combate às falsificações. O próprio governo federal brasileiro, em divulgação de novos produtos com IG no Brasil, afirmou que: " $A$ [IG] funciona como proteção para os produtos contra falsificações, na medida em que garante a sua procedência e amplia o nível de competitividade" (GANDRA, 2011).

A questão das falsificações também é preocupante quando se trata de mercado consumidor estrangeiro. O Vale dos Vinhedos, por exemplo, a mais antiga IG do Brasil, obteve reconhecimento na União Europeia, o que concede credibilidade ao produto naquele mercado e 
serve de garantia para que o consumidor saiba o que está comprando 5 . Nesse, caso a preocupação com as falsificações e o prestígio do produto original ocorre também fora do país de origem, na medida em que o produtor só possui a possibilidade de entrar em juízo contra aquele que estiver utilizando a IG indevidamente quando houver o registro e, igualmente, o consumidor só tem a certeza da existência de controles de produção quando há o registro.

Em outros termos, a IG pode ser uma ferramenta capaz de promover benefícios econômicos concretos aos territórios nos quais está inserida, pois fomenta a economia local, torna os produtos reconhecidos mais competitivos e cria postos de trabalho. Porém, para que tais benefícios possam ser aproveitados, é imprescindível a existência e a utilização de uma proteção jurídica efetiva (tanto interna quanto externa) que proteja os direitos dos titulares das IG e assegure os direitos dos consumidores (LOCATELLI. 2007a).

É o que demonstram os dados compilados de 1997 a 2011 e apresentados no Gráfico 1, adiante, apontando um aumento significativo, sobretudo nos últimos três anos, dos pedidos de IG que deram entrada no INPI.

\section{Gráfico 1. Depósitos de pedidos de indicações geográficas}

\footnotetext{
${ }^{5} \mathrm{Em}$ janeiro de 2007. Nesse sentido, consultar: <http://www.itamaraty.gov.br/salade-imprensa/notas-a-imprensa/2007/02/reconhecimento-da-indicacao-geograficavale-dos $>$.
} 


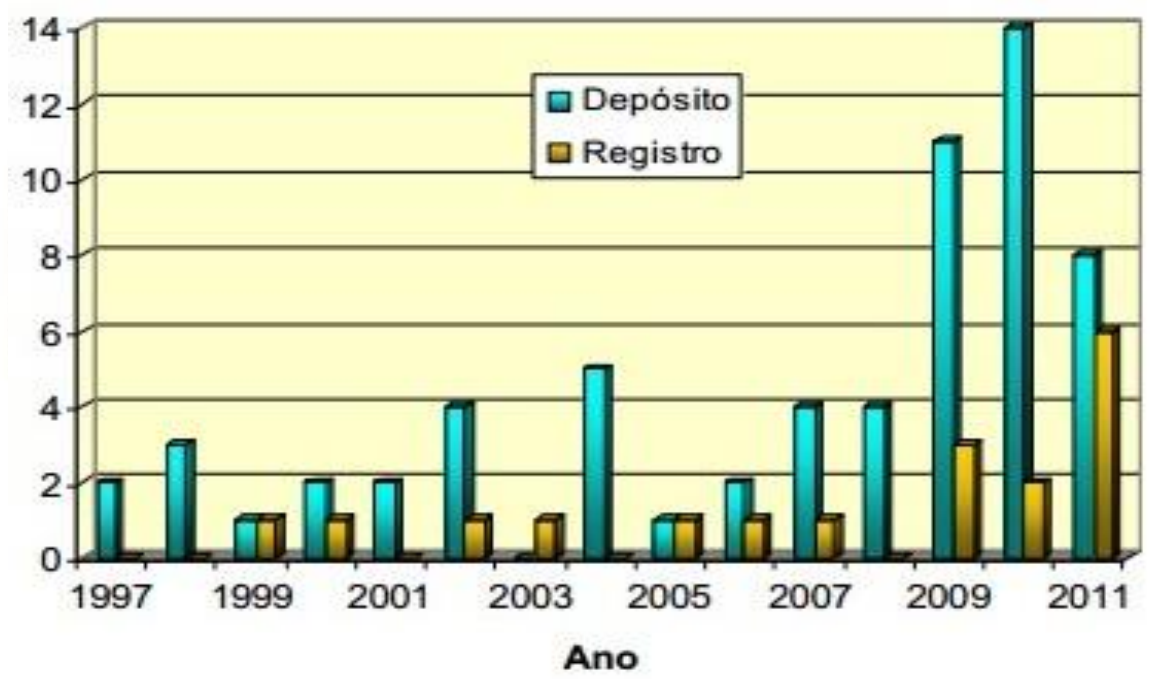

Fonte: BRASIL, 2011.

O aumento nesses números revela que a propriedade intelectual, por meio da IG, encontra-se conectada a um horizonte no qual a reorganização dos territórios de produção e das relações internacionais de trabalho estabelece como sendo fundamental identificar estratégias de desenvolvimento que permitam a sustentabilidade de atividades potencializadoras da dinâmica econômica ao agregar elementos de competitividade aos setores industriais, artesanais ou agroalimentares tradicionais.

Conforme demonstra o Gráfico 2, abaixo, se comparados os depósitos e os registros de concessões, embora ambos os números sejam ainda bastante incipientes, é possível observar uma evolução considerável, o que demonstra que a preocupação do produtor brasileiro em proteger produtos com identidade territorial vem crescendo. 
O Instituto Jurídico da Indicação Geográfica na promoção do Desenvolvimento Regional...

Redes (St. Cruz Sul, Online), v. 20, nº 3 - Suplemento, p. 293 - 313, set./dez. 2015308 


\section{Gráfico 2. Depósitos x Registros}

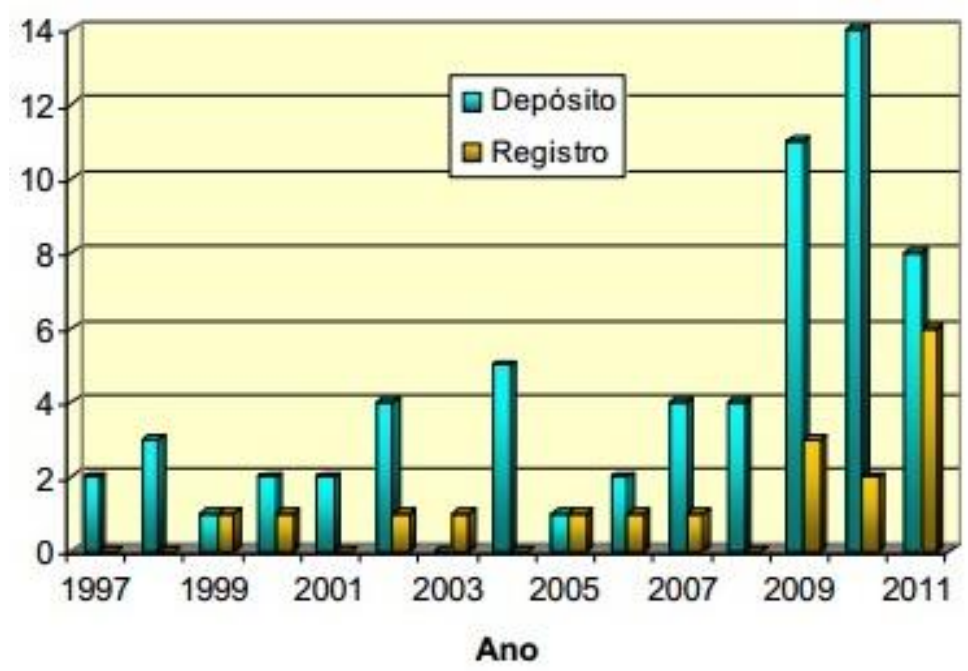

Fonte: BRASIL, 2011.

Todo o interesse demonstrado em relação ao potencial de uma IG registrada como geradora de desenvolvimento está vinculado, também, à proposição sobre a "cesta de bens e serviços" territorializados, desenvolvida por Pecqueur (2006). Para esse autor, embora as recentes evoluções da globalização "[...] estejam suscitando dois problemas importantes: por um lado, a extensão do fenômeno da padronização e, por outro, a descentralização dos processos produtivos", por outro lado, e paradoxalmente, condições como essas são responsáveis por estimular a busca por novos recursos, com características sui generis, isto é, "[...] voltadas para usos específicos e, no limite, não reprodutíveis" (2006, p. 135, grifos nossos).

Com base em experiências empíricas, esse autor aponta a possibilidade de que "[...] os agentes produtivos sediados num dado território podem colocar em prática uma estratégia voltada para uma oferta ao mesmo tempo diversificada [...]", que poderia agregar vários produtos e serviços e "situada", pois vinculada a um território específico, assim como à cultura e à história desse território. A renda obtida por meio dessa nova conformação seria uma renda organizacional, refletindo a capacidade dos atores locais, e seu desenvolvimento 
resultaria da adoção de uma estratégia territorial de longo prazo (PECQUEUR, 2006, p. 136, grifos nossos).

Dessa forma, existindo um produto líder, com qualidade reconhecida em função da origem, poderia ser estabelecido o modelo da cesta, no qual a oferta é situada e combinada. Seria o caso de produtores e prestadores de serviços inseridos no território delimitado pela IG que atingem o consumidor do produto ou serviço com IG, compondo uma cesta que o próprio consumidor elabora. Nesse caso, a origem do produto líder é a responsável por determinar a escolha dos outros produtos ou serviços, de modo que, por meio de uma estratégia de desenvolvimento territorial coletiva, todos se beneficiam direta e indiretamente. No Brasil, o melhor exemplo possível é o roteiro turístico do Vale dos Vinhedos - RS, cuja expressão econômica tomou novos patamares a partir da IG dos Vinhos, beneficiando bares, restaurantes, queijarias e hotéis, entre outros produtos e empreendimentos à disposição do consumidor em função da reestruturação socioeconômica decorrente do registro da IG.

De forma geral, portanto, são múltiplos os benefícios que uma IG, desde que bem administrada, pode gerar para o produtor e à comunidade envolvida. Os mais aparentes são de ordem econômica, em particular a agregação de valor ao produto, o acesso a novos mercados e o combate à falsificação e contrabando. Mas também podem ser benefícios sociais, como o aumento no número de empregos e da renda, ou culturais, tais como a revitalização de atrativos turísticos e o reconhecimento da tradição histórico-cultural. Já para o consumidor final, o principal proveito é a certeza de um produto de qualidade, submetido a padrões de controle.

Esse conjunto de vantagens tem sido tradicionalmente vinculado às IGs de produtos agroalimentares, inclusive por estarem na origem do instituto. Existe possibilidade, no entanto, de produtos não agroalimentares também serem registrados e protegidos por uma IG e sua importância é crescente, particularmente (mas não apenas) na União Europeia - UE.

Nesse sentido, a Comissão Europeia encomendou um estudo já em 2009 sobre as indicações geográficas não agroalimentares porventura existentes nos Estados membros da UE, a fim de que o relatório pudesse subsidiar estudos para elaboração de regras de 
proteção a IGs deste tipo de produto (EUROPEAN UNION, 2009) ${ }^{6}$. Nessa situação, encontram-se inúmeras IGs reconhecidas como a Solinger Schneidwaren, da Alemanha, ou a Couteaux de Thiers, ambas do setor de cutelaria. Também a Koniakow Laces para a renda polonesa, ou ainda a Shetland Woolen Outwear para os têxteis ingleses e a Českýkřištál, para os cristais tchecos.

Posteriormente, em seu "Informe ao Parlamento Europeu", de 2011, a Comissão definiu uma série de projetos no âmbito dos DPIs, dando especial destaque ao tema da IG. De acordo com Kegel; Amal; Carls (2011), a Comissão entendia que faltaria um sistema mais amplo de expansão da IG para produtos não agrícolas, e o impacto econômico previsto apontava que a ampliação da proteção jurídica da IG para este tipo de produto poderia vir a ser extremamente positiva, principalmente nas regiões onde as estruturas produtivas tradicionais sofreram mais intensamente os efeitos da globalização e da nova divisão internacional do trabalho.

Tais exemplos demonstram que o reconhecimento de IG para produtos não agroalimentares é possível, serve de incentivo à reordenação produtiva de determinado setor e, consequentemente, impacta no padrão de desenvolvimento da região. No Brasil, os casos mais conhecidos de IG já reconhecida para produtos manufaturados são o couro acabado do Vale dos Sinos e os calçados de Franca. Nesse contexto, a próxima seção é dedicada às perspectivas e potencial para o reconhecimento de uma IG para o setor de cristais artesanais da região de Blumenau.

\footnotetext{
${ }^{6} \mathrm{O}$ relatório pode ser acessado em:

<http://trade.ec.europa.eu/doclib/docs/2011/may/tradoc_147926.pdf>.
} 


\section{UMA INDICAÇÃO GEOGRÁFICA PARA O SETOR DE CRISTAIS ARTESANAIS DA REGIÃO BLUMENAU}

O início da indústria de cristais na região de Blumenau no Estado de Santa Catarina ocorreu a partir de meados da década de 1940, quando empresários da região contrataram lapidadores na Alemanha e os trouxeram à cidade para beneficiar peças de cristal que, à época, eram importadas. O começo da produção de cristais deu-se poucos anos depois, quando as matérias-primas passaram a ser fundidas na região e, posteriormente, a integralidade do processo de fabricação, desde a fundição até a lapidação dos cristais passou a ser realizado em Blumenau?.

A qualidade das mercadorias produzidas na região de Blumenau e os baixos preços, se comparados com os produtos europeus, permitiram que os cristais se consolidassem no mercado externo. $O$ período de qualificação técnica e a experiência dos artesãos, apesar de significativos, eram remunerados em valores razoavelmente menores do que os pagos pela concorrência da Europa.

Na década de 1990, contudo, a abertura do mercado nacional aos produtos importados fez com muito setores produtivos brasileiros passassem a competir com produtos provenientes do mercado global. Assim foi com os cristais e os similares asiáticos (ou mesmo europeus) nos quais são utilizados vidros industrializados, fabricados mediante processos automatizados e com custos menores, possibilitando a oferta no mercado por preço final inferior ao cristal artesanal.

Nesse cenário, a indústria cristaleira passou a sofrer prejuízos crescentes, pois a fabricação do cristal artesanal demanda uma mão de obra extremamente qualificada e utiliza matéria-prima importada, o que determina um custo final do produto mais elevado. Os produtos maquinados, fabricados com vidro comum, por sua vez, começaram a chegar ao Brasil em média 30\% mais baratos em relação aos produtos artesanais e de vidro cristal (SANTA CATARINA, 2011).

Tal situação ocasionou uma queda vertiginosa nas vendas, causando sérias dificultadas às empresas. Somaram-se a esses fatores, a falta de modernização para alguns tipos de produtos e o crescente

\footnotetext{
7 Uma detalhada descrição das origens do setor cristaleiro em Blumenau pode ser encontrada em SCHIOCHET, 2003.
}

Redes (St. Cruz Sul, Online), v. 20, n 3 - Suplemento, p. 293 - 313, set./dez. 2015312 
endividamento na forma do passivo tributário e trabalhista, ocasionando o fechamento de algumas empresas ou a drástica redução do quadro de pessoal. A indústria de cristal, que outrora havia empregado mais de 3.000 trabalhadores, em 2007, com dificuldade, mantinha menos de 750 (JACOMOSSI, 2009).

Por outro lado, é importante salientar a ausência no Brasil de uma norma que regulamente e determine o que é cristal ou qual sua composição. Na União Europeia, por exemplo, a Diretiva 69/493/CEE, de 15 de dezembro de 1969, unificou as legislações dos estadosmembros em relação ao vidro cristal.

A importância reside no fato de que a distinção entre os numerosos tipos de vidro e suas características físicas é sua composição química, como, por exemplo, o vidro sílica, o vidro alumino silicato, o vidro álcalibário silicato, o vidro cerâmico e o vidro ótico (SCHIOCHET, 2003). São as diferenças químicas na composição do vidro sodo-cálcico e do vidro chumbo (cristal) que determinam as distintas características de transparência, refração, densidade e dureza de diferentes materiais. É o principal motivo pelo qual o cristal, em especial o artesanal, possui qualidades que o diferenciam do vidro comum, de modo a garantir peças de caráter e beleza únicos.

No Brasil, no entanto, inexiste qualquer norma regulamentadora acerca do vidro cristal, seja na Associação Brasileira de Normas Técnicas - ABNT ou no Instituto Nacional de Metrologia, Qualidade e Tecnologia INMETRO. Tal ausência é duplamente prejudicial. Como a maioria dos produtos importados, feita de vidro comum e mediante processos automatizados, é mais barata e vendida no mercado nacional com a denominação cristal, o consumidor leva um produto que julga ser cristal, mas que em realidade não é.

Mas é no setor empresarial que a inexistência de uma norma no Brasil que defina o que é vidro cristal traz consideráveis prejuízos. Isso porque os produtos importados, de qualidade inferior e maquinados, são vendidos a preços menores no país, mas se utilizam da denominação cristal e causam inegável prejuízo aos produtores locais, pois permite que vidros de qualidade inferior sejam comercializados como se cristais fossem. Além disso, há impactos relacionados a enquadramentos tributários equivocados. 
Por outro lado, a falta de parâmetros em qualquer órgão estatal competente sobre a composição do vidro cristal conduz a um enquadramento tributário equivocado. Dados de uma pesquisa realizada com os produtores de cristal remanescentes na região de Blumenau demonstraram que, no custo final do produto, os tributos pesam com cerca de $40 \%$ do preço total, a folha de pagamento, com $25 \%$ e, por fim, a matéria-prima, com $15 \%$. Verifica-se, então, que a principal dificuldade enfrentada pelos produtores de cristal é a carga tributária excessiva e que não corresponde ao produto e suas características. Em particular, o Imposto sobre Produtos Industrializados - IPI, que não faz qualquer distinção entre vidro e cristal, mesmo existindo diferenças nas composições e cuja alíquota de $15 \%$ não distingue produtos com produção em série de produtos artesanais (JACOMOSSI, 2009).

Nesse contexto de crise do setor, a possibilidade de obtenção de uma IG surge como mecanismo de reestruturação e resgate da memória produtiva, bem como de uma posterior implantação da denominada "cesta de bens e serviços" aventada por Pecqueur. No entanto, para que não sejam empreendidos esforços em projetos cujo potencial é relativamente baixo, antes buscar o registro no INPI de uma IG, é importante diagnosticar o real potencial do projeto em questão. Para tanto, o Serviço Brasileiro de apoio às Micro e Pequenas Empresas SEBRAE, por exemplo, desenvolveu um guia de implementação de indicações geográficas cujo objetivo é avaliar o potencial de uma possível IG, seja na modalidade IP ou DO, e que serve de fundamento para a construção de um projeto a ser depositado no INPI.

Nesse cenário, as primeiras questões trazidas no questionário elaborado pelo SEBRAE (GIESBRECHET, 201 1), buscam compreender se o território especificado é conhecido no mercado consumidor como centro produtor, extrator ou fabricante de algum produto específico, e qual produto seria esse. Nesse caso, é possível verificar, tendo por referência elementos como guias turísticos da região, indicações de agências de viagens e recortes de jornal, por exemplo, que a região de Blumenau tem história, tradição e cultura na produção de cristal artesanal expressa, inclusive, no Museu do Cristal existente no município. Ou seja, existe um produto específico, que é conhecido pelo mercado consumidor, vinculado ao território de origem. Além disso, mesmo com o encolhimento do setor diante da crise, a cultura da produção de 
cristais artesanais permanece viva, na medida em que a região ainda é o maior polo de produção de cristal artesanal das Américas, e o único nos moldes na América do Sul (STRAUSS, 2011).

Outras questões apresentadas pelo SEBRAE dizem respeito à existência de: a) características do produto que sejam capazes de diferenciá-los de outros, semelhantes e disponíveis no mercado; e b) características que sejam comprovadamente resultado da produção ou extração do produto identificado na região delimitada.

Em relação ao primeiro quesito, o cristal produzido na região de Blumenau é artesanal e seu resultado visual primoroso decorre da utilização de matéria-prima nobre, especial para produção de cristal, não de vidro. Combinados à sua origem geográfica, esses são fatores que sempre the deram destaque entre produtos semelhantes. Isso porque, em um produto como o cristal, não há que se falar em sabor ou textura, embora se possa falar em espessura, transparência e brilho, atributos que diferenciam o cristal do vidro comum e lhe dão status superior. Já em relação à segunda questão apresentada, pode-se dizer que essas características são encontradas facilmente em produtos agroalimentares, mas não em produtos industrializados ou artesanais. Nesse sentido, o cristal da região de Blumenau está muito mais vinculado às características visuais da qualidade do produto final.

Em seguida, surgem questões como a da possibilidade de vinculação da produção à região delimitada e qual entidade seria a mais adequada para estudar e comprovar essa vinculação. Mais uma vez a literatura chama a atenção para as características ligadas aos aspectos naturais, que não se aplicam ao cristal por tratar-se de produto manufaturado, caso em que estão presentes aspectos humanos imprescindíveis para o resultado final do produto, mas não existem fatores influenciáveis como clima, solo ou relevo (GIESBRECHT, 2011).

A esse respeito é fundamental salientar que, em tese, o cristal artesanal produzido na região de Blumenau pode ser produzido com a mesma qualidade em outro local. Mas apenas na região verifica-se a existência do saber fazer, a notoriedade, a tradição e a cultura da produção constantes ao longo do tempo. Ou seja, assim como em outros países, onde a IG não é restrita a produtos agroalimentares, no Brasil, é possível registrar produtos industriais ou artesanais em função da origem geográfica. Especificamente em relação ao cristal, pode-se 
citar como paradigma a IG "Cristais da Bohemia", reconhecida desde 1967.

Em seguida, é feito questionamento acerca dos fatores de delimitação da área. Nesse caso, o Município de Blumenau e o seu entorno estão historicamente ligados a esse setor produtivo, embora a notoriedade tenha sido alcançada pela cidade pólo da produção. ${ }^{8}$

É importante também esclarecer algumas questões no que se refere ao nível de notoriedade do produto. Um produto pode ter notoriedade regional, estadual, nacional ou internacional. Não se pode dizer que um produto que tenha notoriedade regional não é digno de uma IG, mas é possível afirmar que quanto mais abrangente for a notoriedade, maior será a necessidade de proteção. No caso do cristal da região de Blumenau, pode ser verificada uma notoriedade nacional muito forte, sobretudo no estado produtor e nos grandes centros, como Rio de Janeiro e São Paulo. A notoriedade internacional não pode ser atestada no âmbito deste artigo, pois, apesar da existência de exportações do produto, a comprovação da notoriedade internacional demandaria um trabalho mais direcionado.

Já no que diz respeito às falsificações do produto no mercado, com a utilização do nome tradicional por produtores fora da região de produção, não se pode apontar essa ocorrência com o necessário grau de fundamento. Porém, na medida em que uma parcela considerável de consumidores não sabe diferenciar cristal de vidro comum, em que pese outros produtores não utilizarem a indicação da procedência em questão, induzem o consumidor em erro em função da inexistência de normatização específica, no Brasil, para fabricação e venda de cristais.

Em relação às normas de produção e ao controle do processo, são seguidas as mesmas normas europeias quanto à composição da matéria-prima e o método de produção adotado é o artesanal. 0 controle desse método ou da matéria-prima utilizada, atualmente, é feito individualmente pelos produtores, inexistindo terceira entidade fiscalizadora.

São esses mesmos produtores (empresários) e os trabalhadores do ramo que detêm a memória do saber fazer do produto, constituindo-

\footnotetext{
${ }^{8}$ Esse é o caso, por exemplo, dos doces de Pelotas. Embora Pelotas seja a referência principal dos consumidores, municípios do entorno contribuíram e contribuem fortemente pela manutenção dessa notoriedade.
}

Redes (St. Cruz Sul, Online), v. 20, n 3 - Suplemento, p. 293 - 313, set./dez. 2015316 
se no "grupo de aporte de conhecimento inicial para fins de documentação final do saber produzir tradicional" (GIESBRECHT, 2011, p. 18-19). Esse apontamento conduz ao Regulamento de Uso, documento referencial para que os produtores continuem fabricando $o$ produto com os procedimentos e qualidade que lhe deram a fama e a notoriedade. Neste caso, a existência de uma entidade representativa da coletividade de produtores, é do conhecimento dos atores envolvidos que, para o depósito de pedido de IG, esta entidade deve estar formalizada, sendo esse um de seus objetivos.

Por fim, a sede dos produtores do produto com notoriedade deve ser obrigatoriamente na área delimitada, já que: "Para a Indicação de Procedência, é necessário que, no mínimo, a parte da produção seja realizada na área delimitada", e também que seja possível comprovar essa sede (GIESBRECHT, 2011, p. 20-21). Tais questões não revelam problema, pois é sabido que, embora a matéria-prima seja proveniente de fora de região geográfica especificada, a produção está sediada em Blumenau e entorno, e essa comprovação pode ser feita, facilmente, por meio de comprovação jurídica da sede e de notas fiscais de produção. Nesse aspecto, o caso dos cristais da região de Blumenau é muito parecido com o de IP já reconhecida, o Couro do Vale dos Sinos, que possui a sua notoriedade baseada na transformação do couro. A matéria-prima (couro cru) não é produzida na região, mas, sim, em todo país e até fora dele. Porém, a industrialização desse couro, transformando-o em couro acabado, e que é o que tem notoriedade, é toda realizada no Vale dos Sinos (GIESBRECHT, 2011).

É em virtude, portanto, do grande número de aspectos positivos acima mencionados que os cristais artesanais produzidos na região de Blumenau possuem potencial bastante significativo para obtenção do reconhecimento de uma IG. 


\section{CONSIDERAÇÕES FINAIS}

A proposta deste artigo foi refletir sobre os mecanismos por meio dos quais as relações entre Direito e Desenvolvimento se manifestam de modo concreto no território, ao estudar o instituto jurídico da IG. Apesar de destinarem-se, originalmente, ao combate de falsificações, atualmente as Indicações Geográficas estão conectadas às estratégias locais de revitalização territorial, pois, além de serem ferramentas coletivas de valorização de produtos tradicionais vinculados a determinados territórios, também possuem as funções de agregar valor ao produto e proteger a região produtora (GIESBRECHT, 2011a). Paralelamente, tem sido a busca constante pela valorização de ativos locais decorrente do processo de globalização que impulsionou a busca por estratégias de valorização daquilo que é singular ou tradicional de determinado lugar, e que surge como uma alternativa econômica e de desenvolvimento.

Por outro lado, o desenvolvimento é conectado ao conjunto das relações sociais, aproveitamento dos recursos existentes, e estabelecimento de um ambiente que possibilite a criação de outros recursos diagnosticados como necessários, a fim de promover novas dinâmicas socioeconômicas e atenção às particularidades de cada território.

É possível concluir, portanto, afirmando que a busca pela proteção dos ativos intelectuais tem uma estreita ligação com processos de desenvolvimento. Nesse sentido, quanto mais as normas de propriedade intelectual de um país forem articuladas e consentâneas com suas necessidades e realidade, maior sua potencialidade para desempenhar um papel determinante para o sucesso de estratégias nacionais e locais de desenvolvimento.

No caso específico, o reconhecimento de uma IG para os cristais artesanais da região de Blumenau representa alternativa para dar maior sustentabilidade econômica para o referido setor produtivo e, assim, contornar a crise e seus efeitos negativos. Na feliz expressão de Tonietto; Zanus e Mandelli (2009, p. 109), em um mundo onde as relações comerciais tendem cada vez mais para a globalização, verificase que as IG que não forem organizadas, desenvolvidas e reconhecidas de fato e de direito poderão perder a competitividade, colocando em 
risco o patrimônio histórico, socioeconômico e cultural. Essa perda da competitividade resulta de um custo maior de produção dos produtos de indicações geográficas, em comparação com o custo da produção de commodities.

\section{REFERÊNCIAS}

BARRAL, Welber de Oliveira. Análise da ordem jurídica brasileira sob a ótica do desenvolvimento. In: Direito e desenvolvimento: debates sobre o impacto do marco jurídico no desenvolvimento econômico brasileiro. Brasília: Agência Brasileira de Desenvolvimento Industrial (ABDI), 2010. p.18-23.

BARROS, Maria Eugênia Caldas. Manual de direito da propriedade intelectual. Aracaju: Evocati, 2007.

BOISIER, Sergio. Desarollo (local): De que estámos hablando? In: MADOERY, Oscar; BARQUERO, Antonio Vázquez. (Org). Transformaciones globales, instituiciones y políticas de desarollo local. Rosário: Homo Sapiens, 2001. p. 1-22.

BOURDIEU, Pierre. Capital cultural, escuela y espacio social. México: SigloVeinteuno, 1997.

BRASIL. Instituto Nacional da Propriedade Industrial. Estatísticas. Indicações Geográficas, 2011 . Disponível em:

<http://www.inpi.gov.br/images/stories/IG_Portal.pdf>. Acesso em: 30 nov. 2012.

BRESSER-PEREIRA, Luiz Carlos. O conceito histórico do desenvolvimento econômico. Disponível em: <www.bresserpereira.org.br>. Acesso em: 30 nov. 2012.

CALDAS, Alcides dos Santos; CERQUEIRA, Patrícia da Silva; PERIN, Teresinha de Fátima. Mais além dos arranjos produtivos locais: as Indicações Geográficas protegidas como unidades de desenvolvimento 
local. In: Revista de Desenvolvimento Econômico, Salvador, ano 7, n. 11, p. 5-15, 2005.

CERDAN, Claire; BRUCH, Kelly Lissandra; SILVA, Aparecido Lima da; COPETTI, Michele; FÁVERO, Klenize Chagas; LOCATELLI, Liliana. Indicações Geográficas de produtos agropecuários: importância histórica e atual. In: PIMENTEL, Luiz Otávio (Org.). Curso de propriedade intelectual \& inovação no agronegócio: módulo II, indicação geográfica. 2.ed. Brasília: MAPA (Ministério da Agricultura, Pecuária e Abastecimento); Florianópolis: SEaD/UFSC/FAPEU, p. 26-55, 2010.

COSTA, Gabriela Coelho. O regime internacional das indicações geográficas: um processo em desenvolvimento. 2010.54 fl. Trabalho de Conclusão de Curso (Especialização) - Relações Internacionais, Instituto de Relações Internacionais da Universidade de Brasília. Brasília, 2010. Disponível em:

<http://bdm.bce.unb.br/bitstream/10483/1090/1/2010_GabrielaCoelh oCosta.pdf. Acesso em: 30 nov. 2012.

DUPIN, Luiz Claudio de Oliveira. Diretoria de contratos e indicações geográficas: coordenadoria geral de indicações geográficas e registros: coordenação de fomento de indicação geográfica. Rio de Janeiro: INPI, $2011 . \quad$ Disponível em: <http://www.tecpar.br/appi/Basico_NITs/Basico_2011//ndicacoesGeogr aficas.pdf $>$ Acesso em: 30 nov. 2012.

EUROPEAN UNION. European Comission. Study on the protection of geographical indications for products other than wines, spirits, agricultural products or foodstuffs. nov. 2009. Disponível em:

<http://trade.ec.europa.eu/doclib/docs/2011/may/tradoc_147926.pdf >. Acesso em: 30 nov. 2012.

FLORES, Murilo. Contribuição para o projeto desenvolvimento territorial rural a partir de serviços e produtos com identidade (RIMISP), 2006. Disponível em: $<$ www.fidamerica.org/admin/docdescargas/centrodoc/centrodoc_236.p df $>$. Acesso em: 30 nov. 2012. 
FURTADO, Celso. O mito do desenvolvimento econômico. 5. ed. Rio de Janeiro: Paz e Terra, 1981.

GANDRA, Alana. Mais dois produtos brasileiros obtêm certificação do INPI que os protegerá contra falsificações. Agência Brasil, Brasília, 09 ago. $2011 . \quad$ Disponível em: <http://agenciabrasil.ebc.com.br/noticia/2011-08-09/mais-doisprodutos-brasileiros-obtem-certificacao-do-inpi-que-os-protegeracontra-falsificacoes $>$. Acesso em: 30 nov. 2012.

GIESBRECHT, Hulda Oliveira (Coord.). Guia de implementação de indicações geográficas: orientações para o desenvolvimento de projetos para o reconhecimento de uma indicação geográfica no INPI. Brasília: SEBRAE, INPI, 2011.

JACOMOSSI, Rafael Ricardo. Aglomeração produtiva e desenvolvimento local/regional: um estudo sobre o aglomerado das indústrias de cristais de Blumenau. 2009. 143 f, il. Dissertação (Mestrado em Desenvolvimento Regional) - Programa de Pós-Graduação em Desenvolvimento Regional, Centro de Ciências Humanas e da Comunicação, Universidade Regional de Blumenau, Blumenau, 2009.

KAKUTA, Susana Maria; SOUZA, Alessandra Lolacono Loureiro de; SCHWANKE, Fernando Henrique; GIESBRECHT, Hulda Oliveira. Indicações geográficas: guia de respostas. Porto Alegre: SEBRAE/RS, 2006.

KEGEL, Patrícia Luíza; AMAL, Mohamed. Instituições, Direito e soberania: a efetividade jurídica nos processos de integração regional nos exemplos da União Europeia e do MERCOSUL. Revista Brasileira de Política Internacional: Brasília, v. 52, n. 1, Junho 2009.

KEGEL, Patrícia Luíza; AMAL, Mohamed; CARLS, Suelen. A Indicação Geográfica como vetor de desenvolvimento regional e a possibilidade de sua aplicação no setor de cristais artesanais do Vale do Itajaí. In: II Conferência do Desenvolvimento CODE/IPEA, 2011, Brasília. Anais do I 
Circuito de Debates Acadêmicos IPEA e Associações de Pós-Graduação em Ciências Humanas, 2011.

LOCATELLI, Liliana. Indicações Geográficas e desenvolvimento econômico. In: BARRAL, Welber; PIMENTEL, Luiz Otávio (Org.). Propriedade Intelectual e Desenvolvimento. Florianópolis: Fundação Boiteux, 2007a. p. 233-252.

LOCATELLI, Liliana. Indicações geográficas: a proteção jurídica sob a perspectiva do desenvolvimento econômico. Curitiba: Juruá, 2007b.

PECQUEUR, Bernard. Qualidade e desenvolvimento territorial: a hipótese da cesta de bens e de serviços territorializados. Eisforia: programa de pós-graduação em agroecossistemas - UFSC, Florianópolis, v. 4, n. especial, p.135-153, 2006.

PIMENTEL, Luiz Otávio (Org.). Curso de propriedade intelectual \& inovação no agronegócio: módulo II, indicação geográfica. 2.ed. Brasília: MAPA (Ministério da Agricultura, Pecuária e Abastecimento); Florianópolis: SEaD/UFSC/FAPEU, 2010.

PIMENTEL, Luiz Otávio; BARRAL, Welber. Direito de propriedade intelectual e desenvolvimento. In: BARRAL, Welber de Oliveira; PIMENTEL, Luiz Otávio (Org.). Propriedade intelectual e desenvolvimento. Florianópolis: Fundação Boiteux, 2007. p. 11-34.

SABOURIN, Eric. Desenvolvimento territorial e abordagem territorial conceitos, estratégias e atores. In: Sabourin, Eric, Teixeira, Olívio Alberto (Org.). Planejamento e desenvolvimento dos territórios rurais: conceitos, controvérsias, experiências. Brasília: Embrapa Informação Tecnológica, 2002. p. 21-37.

SANTA CATARINA. Justiça do trabalho de Santa Catarina. Justiça em movimento. Cristais: o valor do trabalho manual: bloco $3 / 3$.

Florianópolis, 2011 . Disponível em:

$<$ http://www.youtube.com/watch?v=QvC_jbyY60s\&list=PL34DDE8E64F 656361 \&index=3. Acesso em: 30 nov. 2012. 
SCHIOCHET, Valmor. Tecnologia, arte e sobrevivência: empreendimentos do ramo de cristais na microrregião de Blumenau/SC. Blumenau, 2003. Relatório. Universidade Regional de Blumenau.

SEN, Amartya Kumar. Desenvolvimento como liberdade. São Paulo: Cia. das Letras, 2000.

SIEDENBERG, Dieter Rugard. In: Desenvolvimento regional. In: SIEDENBERG, Dieter Rugard (Coord.). Dicionário de desenvolvimento regional. Santa Cruz do Sul: Edunisc, 2006. p. 71-73.

SOUZA, Cristiane Mansur de Moraes; THEIS, Ivo Marcos. Desenvolvimento regional: abordagens contemporâneas. Blumenau: Edifurb, 2009.

STRAUSS, Cristallerie. História e Processo de produção [DVD]. Blumenau. SPRY, 2011.

TONIETTO, J.; ZANUS, M. C.; MANDELLI, F. A incorporação de tecnologias para a sustentabilidade das regiões demarcadas por indicações geográficas de vinhos no Brasil. In: BOFF, S. O.; PIMENTEL, L. O. (Org.). Propriedade intelectual, gestão da inovação e desenvolvimento: patentes, marcas, software, cultivares, indicações geográficas, núcleos de inovação tecnológica. Passo Fundo: IMED, 2009.

Submetido em $18 / 04 / 2014$

Aprovado em 26/11/2015

Sobre os autores

Patrícia Luiza Kegel

Doutora em Direito Internacional pela Universidade Federal de Santa Catarina (UFSC). Professora no Programa de Pós-Graduação em Desenvolvimento Regional na Universidade Regional de Blumenau (FURB). Membro fundador da "European Union StudiesAssociation" - Brasil. Membro da Lista Brasileira de Terceiros Árbitros do MERCOSUL. Pesquisadora do "Zentrum für Europäische Integrationsforschung" (ZEI), da Universidade de Bonn.

E-mail: paluke@furb.br

Suelen Carls

Redes (St. Cruz Sul, Online), v. 20, n 3 - Suplemento, p. 293 - 313, set./dez. 2015323 
O Instituto Jurídico da Indicação Geográfica na promoção do Desenvolvimento

Regional...

Doutoranda em Direito na Universidade Federal de Santa Catarina (UFSC). Mestre em Desenvolvimento Regional, Especialista em Gestão Tributária e Bacharel em Direito, todos pela Universidade de Blumenau (FURB).

E-mail: su.carls@gmail.com 